\title{
Value Interpretation and Realization Path of Social Justice in a Harmonious Society
}

\author{
Yadi Wang \\ Teaching Department of Political Theory, Nanyang Institute of Technology, Nanyang, Henan, China
}

Keywords: Social Justice; Value Interpretation; Realization Path; Harmonious Society; Scientific Development.

\begin{abstract}
In the context of building a harmonious society, social justice has once again become the core and primary content of the social value system, and has become a major historical task of building and developing socialism with Chinese characteristics. Since the reform and opening up policy has made huge material progress, seeking for social justice will supplement each other with practicing scientific outlook on development and maintaining fast and steady development of economic society. Therefore, it is important to understand the value of social justice and explore the path of social justice in the new historical situation.
\end{abstract}

\section{Introduction}

Social justice has the ultimate meaning in the development of human society. Rawls pointed out in his book A Theory of Justice published in 1971, "Justice is the first virtue of social institutions, as truth is of systems of thought. All social values, both freedom and opportunity, income and wealth, and self-esteem or dignity, should be equally distributed, otherwise any unequal distribution will be at least detrimental to one person" . 1 However in Romer's points of view, it is difficult for society to achieve complete justice, and the source of social injustice often comes from the difference in the initial allocation of means of production. In the context of building a harmonious society, social justice has once again become the core and primary content of the social value system, and has become a major historical task of building and developing socialism with Chinese characteristics. 2 Since the reform and opening up policy has made huge material progress, seeking for social justice will supplement each other with practicing scientific outlook on development and maintaining fast and steady development of economic society. Therefore, it is important to understand the value of social justice and explore the path of social justice in the new historical situation.

\section{The Fundamental Starting Point of Social Justice and the Criticism of Injustice}

The Fundamental Starting Point. In the realization system of social justice, the fundamental starting point is to protect the legitimate interests of every social member and social group, and to "make them gain what they deserve". 3 From the perspective of social justice, every social group and social member has the most basic human right to exist. This right should be protected without any additional conditions. In addition, it should provide the necessary space for every social group, every social member. In this space, the idea and potential ability of social groups or individuals are able to be maximized to realize the benefit sharing between social groups, social groups and social members, and individuals.

From a macro perspective, in any realistic social system, any social member or social group is likely to encounter the opposite of the "social justice". They are likely to be in an "unfair" situation, even if the levels and angles are different. 4 In this case, the country will play its "justice" function. It should stand on the position of the overall social interests and treat those who need attention and help with a fair and just attitude. This is to maintain the equal rights and reasonable interests of every social group and members of society. 
The Criticism of Injustice. At present, the phenomenon of social injustice in our society still exists to a certain extent, and has formed a "shaky force" to the fundamental starting point of social justice, which profoundly affects the ultimate realization of social justice. The social injustice is mainly focus on the following aspects:

Injustice in the Field of Income Distribution. In recent years, the gap between rich and poor in our country is showing an increasing trend, and the root cause of this phenomenon is the injustice of income distribution. 5 For example, the income gap between urban and rural areas is gradually increasing; The suddenly rising cities or the suddenly downfallen cities or regions intensify the industry's progress and recession; The central and western regions are catching up with some of the eastern coastal cities that were the first to rise; Per capita income in some rural areas has exceeded that of urban areas; The development of regional economy shows the trend of "reverse force", etc.

Injustice in the Field of Medical Health. From the present situation in our country, the "20/80 principle" of management still exists, which seriously affects social justice. For example, in China, the rural population accounts for about $80 \%$ of the total population, but this social group only accounts for about $20 \%$ of the medical health resources of all the society. Although rural cooperative medical service has been introduced in many rural areas, the rights of farmer groups in the aspect of medical health have not been significantly improved. There is much more to do. In contrast, "Strong groups" (high-income groups, high social status groups, etc.) have medical health insurance with various forms and higher levels.

Injustice in the Field of Education. The injustice of the field has been widely mentioned in the whole society. But even today, the justice in the field of education is still at a low level. For example, there are significant differences in the allocation of education resources in different regions of our country (divided as Eastern, Western, Southern, Northern and Middle). The education resources and education chances are also unequal between cities and countryside. Even within the same area, the distinction between key and non-key schools is obvious.

\section{The Negative Value of Social Injustice}

Political Exclusion Led by Social Injustice. For any democratic country, the vision of "equality for all" is established from the legal system level, and it is the basis for eliminating the exclusion of social groups and social members at the political level.6 In the real world, however, human life and production will inadvertently "distort" the right relationship between humans. The resulting social injustice will lead to political exclusion in the real world. In general, political exclusion often manifests in two aspects: In the aspect of dominance, it mainly points to the social groups and members of society are excluded from losing political rights. In the aspect of recession, it mainly points to the social groups and members of society who used to have political rights are unable to participate in political activities. For example, some poor people or homeless people will be unable to participate in normal social life due to economic reasons.

Cultural Exclusion Led by Social Injustice. Social exclusion on the cultural level is an recessive exclusion. One of the most obvious and influential one is "cultural centralism". In general, the strengthening of understanding and communication between social groups and members of society can effectively reduce cultural exclusion.7 This kind of cultural exclusion caused by social justice is often manifested in the following two aspects: On one hand, some cultures will be rejected by other cultures or mainstream cultures if it is hard to preserve their own cultural traditions. On the other hand, if social groups or members of society with particular cultures are difficult to choose a way of life in accordance with their own requirements, they will "choose" to suffer cultural exclusion.

Economic Exclusion Led by Social Injustice. Social justice can bring fair opportunities to social groups and members of society, which can make them be treated equally in the process of obtaining labor and living materials. But social injustice will discourage social organizations(for example, the smallest unit of society-the family) and members(especially members in poor areas) from participating in production and social activities, which indirectly affects their rights to allocate productions and obtain resources in the consumption field.8 In this way, one of the most immediate consequences will happen - poverty. 


\section{The Return of Social Justice Reflects the Value of Social Integration}

The Return of Social Justice Can Reduce the Contradiction between the Subjects of Interest. Since the reform and opening up, there has been a contradiction between the different interest subjects in our society. These contradictions (some are directly in the form of conflict) have become difficult to resolve over the years, and are extremely detrimental to the establishment of a harmonious society. These contradictions are between cadres and the masses, high and low income groups, capital owners and the labor force. Moreover, there is no declining trend of these contradictions, and they are even accumulating and enlarging, which bring big risks. The risks are mainly in the following respects: Contradictions between interest subjects will undermine the cohesion of social groups and members of society; The escalation of contradictions can directly affect the sustainable development of the economy and society; The long-term existence of contradictions is bound to threaten the establishment of harmonious society, and make the value of social integration at a low level. 9-10 So, it is necessary to emphasize the return of social justice, guide interest pursuit of social groups and members with the idea of social justice, effectively reduce and lower the contradictions between the interest subjects, and promote the harmonious and orderly development of the economic society.

The Return of Social Justice Can Narrow the "Interest Gap" between the Interest Subjects. In the analysis of China's reform and opening-up strategy and national policies in recent years, it is found that the social reform in China is the type of "inspire" and the type of "difference", which means by creating the differences between the interest subjects, more social groups and individuals are encouraged to pursue more interests. In this way, the original undifferentiated interest distribution pattern is broken. Instead, the interests based on new principles are redistributed among social groups or members of society. In this way, the process of social reform in our country has kept pace with the process of interest differentiation between interest subjects.11 as the reform process continues to advance, this differentiation continues to accumulate and ferment. Therefore, we need to re-examine the norms of social justice. Only by realizing the return of social justice can we narrow the gap between interest subjects. Only by realizing the return of social justice can we put efficiency and justice in the same place when dealing with them and realize the harmony and development of the society.

\section{The Path of Social Justice in the Harmonious Society}

Satisfy the Will of the Public's Rights to Be Respected, Build a Model of Social Selection with a Fair Start Point and Equal Opportunities. According to Rawls, "fair start" and "equal opportunities" are the basic prerequisites for achieving fair results. So, on the issue of social justice, it is impossible to achieve the ultimate goal of social justice without a fair starting point and an equal chance. For example, the intensity of basic education investment should be increased to ensure social groups and the public who are in the "depression" area of education enjoy their basic right. At the same time, the excellent education resources should be transferred to the "depression" area of education, allowing them to be at the same level as other groups eventually. Specifically, led by the government, the country should break the existing uneven distribution of educational resources, expand the investment scale of the rural areas and remote areas to ensure a fair start point.

Reflect a Wider Range of Social Justice through the Reform of Income Distribution System. At present, our society is in a period of transition and a crucial period of reform and opening up. In this process, some problems about institutional mechanism of economic and social development needs to be solved through the regime reform. On this issue, the reform of the income distribution system is essential. This is because income levels can affect the flow of human resources to a large extent. When the monopoly, power rent-seeking and other factors that affect the distribution of income, the efficiency of human resources allocation will be significantly reduced. So, the amount of social security contributions needs to be reduced. Moreover, the pension insurance can be supplemented through the form of the dividends of state-owned enterprises. This will not only reduce the burden on residents, but also will not affect the treatment of social insurance. In this way, the income gap between the subjects of social interest will be significantly narrowed. At the same time, it 
can also promote employment, increase the disposable income of the residents, and indirectly improve the efficiency of investment, etc.

The Realization of Social Justice Needs to Be Ensured by the Justice of the Rule of Law. From the national level, the democratic country is firstly a country under the rule of law. Thus the realization of social justice needs to be ensured by the justice of the rule of law. And legislative justice and judicial justice should be achieved at the same time. Only when these two aspects are unified and coordinated, the reform of social system can be carried out smoothly until the desired effect is revealed. In this way, it is the most direct and effective way to build and protect social justice by strengthening the construction of socialist rule of law and realize the justice of the socialist rule of law.

All in all, the realization of social justice and the construction of a harmonious socialist society have become the social ideal and ultimate value target that the people of our country are pursuing. But any society in the process of realizing social justice will face all kinds of problems. As a long, progressive historical process, the realization of social justice should be closely coordinated with the development of the country; the interests of social groups and the public should be re-integrated by necessary means; the interests differentiation should be reduced to ensure the justice of interests; all kinds of crises arising from the differentiation of interests should be Controlled and resolved. By adopting these measures, the process of a harmonious society will not be hindered, the value of social justice can be maximized.

\section{Acknowledgements}

Fund Project: This paper is the Phased Achievement of the Philosophy and Social Science Project of Hennan "The Study on the Leading Value and Reality Reflection of the View of Social Justice in the New Normal" (2016BZZ008).

\section{References}

[1] [America]John Rawls. A Theory of Justice [M]. translated by Huaihong He, etc. Beijing: China Social Sciences Publishing House, 1988.

[2] Decision of the Central Committee of the Communist Party of China on several important issues in Building a Socialist Harmonious Society [N].People's Daily, 2006-10-19.

[3] Jiabao Wen. The Historical Tasks of the Primary Stage of Socialism and the Problems of the Foreign Policy [N]. People's Daily, 2007-2-27.

[4] Rui Lu, Lei Qu. China 's Current Social Management from the Angle of Social Justice [J]. Journal of Shanxi Youth Management Cadre College, 2012 (1): 51-54.

[5] Xinwei Pu. Reducing Social Exclusion is an Important Way to Promote Social Justice [J]. Journal of Jilin Province Economic Management Cadre College, 2009 (4): 9-12.

[6] Jin Zhang. The Methodological Significance of Romer's Social Justice Thought [J]. Journal of Zhongbei University (social science edition), 2008 (3): 17-20.

[7] Hui Liu. Social Justice: the Basic Norms of Contemporary Chinese Social Integration [J]. Qilu Journal, 2011 (1): 86-89.

[8] Xiangfeng Kong. The Justice of Rule of Law is an Effective Step to Realize Social Justice [J]. Journal of Shenyang Institute of Engineering (social science edition), 2007 (1): 73-80.

[9] Xiaoxiong Liu. From Economic Justice to Social Justice [J]. Journal of Nanchang Vocational \& Technical Teachers' College, 2002 (10): 25-27.

[10] Shuang Sun. Social Justice and its Realization Path in the Harmonious Society [J]. Journal of Management, 2010 (6): 57-60.

[11] KARL MARX and FREDERICK ENGELS: Volume 1 [M]. Beijing: People's Publishing House, 1995. 